\title{
Early rheumatoid arthritis 6 years after diagnosis is still associated with high direct costs and increasing loss of productivity: the Swedish TIRA project
}

Eva Hallert, Magnus Husberg, Almina Kalkan, Thomas Skogh and Lars Bernfort

\author{
Linköping University Post Print
}

\section{Tweet}

N.B.: When citing this work, cite the original article.

Original Publication:

Eva Hallert, Magnus Husberg, Almina Kalkan, Thomas Skogh and Lars Bernfort, Early rheumatoid arthritis 6 years after diagnosis is still associated with high direct costs and increasing loss of productivity: the Swedish TIRA project, 2014, Scandinavian Journal of Rheumatology, (43), 3, 177-183.

http://dx.doi.org/10.3109/03009742.2013.835442

Copyright: Informa Healthcare

http://informahealthcare.com/

Postprint available at: Linköping University Electronic Press

http://urn.kb.se/resolve?urn=urn:nbn:se:liu:diva-105634 


\section{Early rheumatoid arthritis 6 years after diagnosis is still associated with high direct costs and increasing loss of productivity (the Swedish TIRA project).}

Eva Hallert ${ }^{1,2}$, Magnus Husberg ${ }^{1}$, Almina Kalkan $^{1}$, Thomas Skogh ${ }^{3}$, Lars Bernfort ${ }^{1}$

1 Center for Medical Technology Assessment, Department of Medical and Health Sciences, Faculty of Health Sciences, Linköping University, Linköping, Sweden.

2 Department of Cardiovascular Diseases \& Speciality Medicine, University Hospital, Linköping, Sweden.

${ }^{3}$ AIR/Rheumatology unit, Department of Clinical and Experimental Medicine Faculty of Health Sciences, Linköping University Hospital, Linköping, Sweden.

\section{Abstract}

Objectives. To calculate total costs during 6 years after diagnosis of early rheumatoid arthritis.

Methods. In the longitudinal prospective multicenter TIRA study, 239 patients from 7 units, diagnosed 1996-98, reported regularly health care utilization and number of days lost from work. Costs were obtained from official databases and calculated using unit costs (Swedish kronor, SEK) from 2001. Indirect costs were calculated using human capital approach. Costs were inflation-adjusted to Euro June 2012, using Swedish Consumer Price Index and exchange rate June 2012. Statistical analyses were based on linear mixed models (LMM) for changes over time.

Results. Mean total cost/patient was $€ 14768$ in year 1 and increased to $€ 18438$ in year 6 . Outpatient visits and hospitalization decreased, but costs for surgery increased from $€ 92 /$ patient year 1 to $€ 444$ year 6 . Drugs increased from $€ 429 /$ patient to $€ 2214 /$ patient, mainly due to introduction of biologics. Year 1, drugs made up for $10 \%$ of direct costs and increased to $49 \%$ in year 6 . Sick leave decreased during the first years, but disability pensions increased, resulting in unchanged indirect costs. Over the following years, disability pensions increased further and indirect costs increased from $€ 10284$ year 1 to $€ 13874$ year 6. LMM analyses showed that indirect costs were unchanged while direct costs, after an initial drop, increased over the following years, leading to increasing total costs.

Conclusions. Drug costs were partially offset by decreasing outpatient visits but indirect costs remained unchanged and total costs increased.

\section{Key words}

early rheumatoid arthritis, health economics, direct costs, indirect costs, prospective longitudinal study, Health Assessment Questionnaire, Disease Activity Score-28 


\section{Introduction}

Insufficiently treated, rheumatoid arthritis $(R A)$ is a chronic progressive inflammatory disease leading to disability, pain and reduced quality of life (1). Although costs caused by healthcare utilization are high, the total costs are mainly driven by loss of working capacity (2-5). Major advances regarding aetiopathogenis, diagnostics, disease classification, pharmacotherapy and structured follow-up of patients with RA have radically changed clinical routines regarding treatment of RA (6). Starting with the introduction of tumor necrosis factor (TNF) inhibitors around year 2000, a wide range of other biological anti-rheumatic agents have been added to the list, and new targeted drugs are expected $(7,8)$. The new principles have revolutionized and markedly improved the management of patients with RA, but have also increased direct costs, which are now predominantly driven by drug costs (9-11). A number of clinical trials have demonstrated that patients benefit from biological drugs with substantial improvements in health status (7-9). However, results from longitudinal observational studies imply that the positive effects of biologic anti-rheumatic drugs are less pronounced in real life, compared to those reported in clinical trials, hence giving higher costs per qualityadjusted life year, compared to estimates from clinical trials (10). Based on the Swedish TIRA project (acronym for early intervention in RA), we have previously reported that direct and indirect costs were very high during the first years following diagnosis of early RA $(3,12)$. The present study was done during a period when biologic drugs were introduced in Swedish clinical routine and the aim was to calculate direct and indirect costs in patients with early RA in Sweden during the 6-year period following diagnosis.

\section{Patients and methods}

\section{Patients}

The present study is based on a 6-year follow-up of 239 patients recruited to the Swedish TIRA study 1996-98. TIRA is a prospective cohort of early ( $\leq 12$ months) RA and involves regular assessments by physiotherapists, occupational therapists and nurses in addition to the interventions and structured follow-up by physicians (12). Ninety-five percent of the patients fulfilled at least 4/7 criteria according to the 1987 revised ACR criteria (13) and the remainder suffered from morning stiffness ( 60 minutes or more as judged by the patients), symmetrical joint affection and arthritis in small joints (fingers/toes).

\section{Clinical and laboratory assessments}

Clinical and laboratory data were collected at inclusion, and after 3, 6, 12, 18 and 24 months, and then annually. Details of the study have been described previously (12). Briefly, tender and swollen joint counts were registered, erythrocyte sedimentation rate (ESR) was analysed and the patient's global assessment of disease activity was estimated on a 100$\mathrm{mm}$ visual analogue scale (VAS) and the 28-joint count disease activity score (DAS28) was calculated (14). The physician also scored (0-4) global assessment of disease activity (PGA). Serum levels of C-reactive protein (CRP) were analysed as well as IgM-class rheumatoid factor (RF) and antibodies to the $2^{\text {nd }}$ generation cyclic citrullinated peptide (CCP2) as described in detail previously (15). Patients reported pain on VAS and completed the Swedish version of Health Assessment Questionnaire (HAQ) (16). On-going, instituted, and withdrawn medication with Assessment Questionnaire (HAQ) (16). On-going, instituted, and withdrawn medication with disease-modifying anti-rheumatic drugs (DMARDs), nonsteroidal anti-inflammatory drugs (NSAIDs), corticosteroids, and analgesics was registered at all visits.

\section{Health economic questionnaire}

Demographic and socioeconomic data, including age, sex, marital status, educational level and employment status were collected at inclusion. During the first 2 years, the patients were provided with health economic questionnaires every 6 months and thereafter once a 
year. The questionnaires were kept as diaries and patients reported prospectively all RArelated outpatient visits as well as admissions to hospital and surgical procedures. Dosage and frequency of all prescribed drugs was reported as well as drugs bought over the counter. In case complementary medicine, such as herbal medication and chiropractic therapy, was used, this was also reported. The number of days on sick leave or days with RA-related disability benefits during the period was reported and the health-related qualityof-life instrument EuroQol-5D (EQ-5D) was completed. Costs were calculated using unit costs from 2001 and inflation-adjusted to Euro June 2012, using the Swedish Consumer Price Index (18\% increase 2001-2012) and the exchange rate in June $2012 € 1=$ SEK 8.8772 $(17,18)$. No discounting was used.

\section{Direct costs}

Costs were calculated using the official Swedish County Council tariffs for outpatient visits to physician, physiotherapist, nurse and occupational therapist. These tariffs were elaborated by including all types of overhead costs involved in the patient visit, such as administration costs, laboratory analyses, radiographs, salaries of relevant staff involved in the visit etc. The unit cost for an outpatient visit to physician was $€ 227$ and to physiotherapist, occupational therapist or nurse $€ 76$ (19). Costs for surgery, including total costs for surgical interventions and a standardized number of hospital days were calculated according to the NordDRG system (20). The cost for total joint replacement of hip or knee was $€ 8309$, major foot surgery $€ 3584$ major hand/elbow surgery $€ 2069$ and minor hand/foot surgery $€ 1337$. Additional hospitalization, besides standard care, was calculated as additional days, estimating a day in hospital to $€ 302$. Drug costs were calculated using dosage and duration multiplied by unit costs using market wholesale prices (21). Total costs were calculated, applying a societal perspective, encompassing all costs, regardless of payer. Non-medical costs such as costs for transportation and assistive devices were not included in the present study.

\section{Indirect costs}

Indirect costs were calculated, using the human capital approach, estimating the value of lost production during the entire period of absence. The cost applied to 1 day was $€ 108$ and was estimated similarly for sick leave and for early retirement. It was calculated using the average productivity cost of all gainfully employed Swedish full-time workers, corresponding to $€ 3243 /$ month (including taxes and other fees) (17). Loss of productivity was calculated using the number of days on sick leave or disability benefits (including non-working days). In order to describe loss of productivity similarly for the patients, all days have been recalculated to full-time days, for instance 1 full-time day is equal to 2 days with $50 \%$ or 4 days with $25 \%$.

\section{Ethics considerations}

All patients gave written informed consent to participate. The study protocol was approved by the regional ethics committee in Linköping.

\section{Statistics}

Data are presented as mean values with standard deviation (SD) or 95\% confidential interval $(\mathrm{Cl})$ or as proportions. A linear mixed model for longitudinal analysis was performed with repeated measurements for associations over time to examine within-subject difference in intercept and slope, tying all observations from the same patient together. The development of each cost was explored with a linear or quadratic effect over time. Level of significance was set at 0.05. All analyses were performed using IBM SPSS 20.0. 


\section{Results}

At the 6-year follow-up, 171 patients (72\%), still remained in the study and complete health economic data was available for 125 patients. Patients were lost to follow-up for reasons such as having moved from the area, declining further participation because of "too many tests", having difficulties with transportation to the hospital, etc. Except for slightly higher average age among patients lost to follow-up, there were no baseline demographic or clinical differences between the patients with health economic data and patients without such data available. Baseline data for the study group is presented in table 1.

Table 1. Baseline demographic and clinical characteristics of the study group. Values are mean $(S D)$ unless otherwise mentioned.

\begin{tabular}{lr} 
Age (years) & $55(13)$ \\
Women (\%) & $67 \%$ \\
>65 years (\%) & $30 \%$ \\
Sick leave or DP (\%)* & $57 \%$ \\
Education >12 yrs (\%) & $32 \%$ \\
Living with partner (\%) & $77 \%$ \\
Swollen joints (0-28) & $9.4(6.0)$ \\
Tender joints (0-28) & $9.4(7.5)$ \\
ESR (mm/hour) & $35(24)$ \\
Global VAS (0-100 mm) & $47(24)$ \\
DAS28 & $5.3(1.1)$ \\
CRP (mg/l) & $27(26)$ \\
Pain VAS (0-100 mm) & $51(25)$ \\
PGA (0-4) & $2.0(0.8)$ \\
Anti-CCP+ (\%) & $67 \%$ \\
RF+ (\%) & $73 \%$ \\
HAQ (0-3) & $0.9(0.6)$ \\
\hline
\end{tabular}

*percentage of patients $<65$ on sick leave or with disability pension (DP) at inclusion. ESR=erythrocyte sedimentation rate, VAS $=$ visual analogue scale, DAS28 $=28$ joint-count disease activity score, $\mathrm{CRP}=\mathrm{C}$-reactive protein, $\mathrm{PGA}=$ physician's global assessment of disease activity, anti-CCP = antibodies against cyclic citrullinated peptides, $\mathrm{RF}=$ IgM-class rheumatoid factor $\mathrm{HAQ}=$ Health Assessment Questionnaire

\section{Direct costs}

The total number of outpatient physician visits decreased during the first years, but increased again after year 3 . Visits to the nurse, mainly for drug monitoring, decreased during the first 4 years and were then stabilized on a lower level. A similar pattern was seen for visits to physiotherapist and occupational therapist. Number of days in hospital also decreased during the first 4 years, but increased again in year 5 and 6 . Mean costs for complementary medicine (CAM) were rather low, as this was used by few patients. Drug costs, however, increased every year and this was particularly evident from year 3 and onwards. Costs for surgery were rather low year 1 and 2, but increased substantially over the following years. During the time between year 3 and year 6 , in total 32 patients were prescribed biologics at various time points. DAS28 improved from 5.3 at inclusion to 3.3 at 6 year follow up, while HAQ after initial improvement, slowly deteriorated (Table 2). 
Table 2. Physical units with mean (SD) number of outpatient visits, days in hospital and number of full-time days with sick leave and disability pension for each year during 6 years after diagnosis. Direct and indirect costs $(€)$ and HAQ and DAS28 scores during 6 years, mean $(S D)$.

\begin{tabular}{|c|c|c|c|c|c|}
\hline $\begin{array}{r}\text { Year } 1 \\
(n=210)\end{array}$ & $\begin{array}{r}\text { Year } 2 \\
(n=191)\end{array}$ & $\begin{array}{r}\text { Year } 3 \\
(n=153)\end{array}$ & $\begin{array}{r}\text { Year } 4 \\
(n=118)\end{array}$ & $\begin{array}{r}\text { Year } 5 \\
(n=133)\end{array}$ & $\begin{array}{r}\text { Year } 6 \\
(n=125)\end{array}$ \\
\hline
\end{tabular}

\begin{tabular}{lllllll}
\multicolumn{2}{l}{ Physical units $(\mathbf{n})$} \\
physician & $4.5(2.5)$ & $3.2(2.0)$ & $2.1(2.1)$ & $2.5(2.4)$ & $2.5(2.3)$ & $2.8(3.0)$ \\
nurse & $9.2(4.0)$ & $6.4(4.0)$ & $6.0(3.2)$ & $2.2(3.0)$ & $2.4(3.6)$ & $3.4(5.9)$ \\
PT, OT & $15.9(16.8)$ & $10.7(19.7)$ & $6.7(14.3)$ & $5.2(8.6)$ & $7.3(13.8)$ & $5.3(8.4)$ \\
inpatient & $1.3(5.9)$ & $1.0(4.8)$ & $0.6(3.1)$ & $0.4(3.1)$ & $1.0(3.8)$ & $0.7(5.4)$ \\
sick leave & $58(107)$ & $41(88)$ & $31(83)$ & $18(52)$ & $16(46)$ & $31(75)$ \\
DP & $18(68)$ & $33(87)$ & $42(105)$ & $70(136)$ & $73(138)$ & $141(161)$
\end{tabular}

\section{Costs (€)}

$\begin{array}{lrrrrrr}\text { total dir costs } & 4485(3674) & 3509(3646) & 3433(4279) & 3799(5939) & 4420(6331) & 4564(5964) \\ \text { physician } & 1248(707) & 879(557) & 581(591) & 709(670) & 690(655) & 792(848) \\ \text { nurse } & 857(368) & 592(367) & 562(298) & 208(282) & 222(331) & 317(549) \\ \text { PT, OT } & 1345(1358) & 861(1316) & 543(1065) & 476(785) & 681(1284) & 489(786) \\ \text { drugs } & 429(518) & 613(950) & 1108(2763) & 1716(4172) & 1978(4515) & 2214(4571) \\ \text { CAM } & 44(162) & 38(139) & 32(193) & 56(236) & 46(162) & 35(125) \\ \text { surgery } & 92(757) & 165(905) & 420(2104) & 480(1926) & 447(2216) & 444(1908) \\ \text { inpatient } & 469(2193) & 361(1714) & 186(948) & 157(1171) & 355(1414) & 274(1990) \\ \text { total indir } & 10284(16702) & 10008(17157) & 9949(17538) & 11565(19026) & 12515(19109) & 13874(20273) \\ \text { sickleave } & 7884(14529) & 5578(12027) & 4244(11339) & 2404(7058) & 2516(6813) & 2505(8119) \\ \text { DP } & 2400(9287) & 4430(11883) & 5704(14284) & 9160(18225) & 9999(18814) & 11369(19324) \\ \text { total costs } & 14768(17779) & 13516(17965) & 13381(19013) & 15374(20697) & 16935(21687) & 18438(21710)\end{array}$

Disease activity and function (score)

$\begin{array}{lrrrrrr}\text { DAS28 } & 3.8(1.4) & 3.7(1.5) & 3.6(1.5) & 3.4(1.3) & 3.5(1.3) & 3.3(1.4) \\ \text { HAQ } & 0.63(0.57) & 0.65(0.55) & 0.66(0.60) & 0.68(0.57) & 0.74(0.58) & 0.68(0.60)\end{array}$

$\mathrm{PT}, \mathrm{OT}=$ physiotherapist, occupational therapist, $\mathrm{CAM}=$ complementary medicine, $\mathrm{DP}=$ disability pension, DAS28=28 joint-disease activity score, $\mathrm{HAQ}=$ Health Assessment Questionnaire

A linear mixed model was performed for associations over time and showed that costs for sick leave decreased by $€ 952$ every year $(p<0.0001)$ and costs for disability pensions increased by $€ 1328$ every year $(p<0.0001)$, resulting in no significant change in total indirect costs. Costs for inpatient care decreased by $€ 29$ ( $p<0.0001)$ while costs for drugs increased by $€ 300$ every year $(p<0.0001)$ and costs for surgery increased by $€ 66 / y e a r(p=0.011)$. The quadratic model was a slightly better fit for outpatient care and total direct costs. All coefficients for linear and quadratic models are shown in table 3. 
Table 3. Coefficients for linear and quadratic models with statistical significant changes over time.

\begin{tabular}{|c|c|c|c|c|c|c|c|c|c|c|}
\hline & & & Linear & & & & Qua & Iratic & & \\
\hline & Interc & $\mathrm{p}$ & $\begin{array}{l}\text { Time, } \\
\text { coeff }\end{array}$ & $p$ & Interc & $p$ & $\begin{array}{l}\text { Time, } \\
\text { coeff }\end{array}$ & $p$ & $\begin{array}{l}\text { Time }^{2}, \\
\text { Coeff }\end{array}$ & $p$ \\
\hline $\begin{array}{l}\text { total dir } \\
\text { costs }\end{array}$ & 3189 & 0,000 & -11 & 0,890 & 3545 & 0,000 & -675 & 0,000 & 144 & 0,000 \\
\hline physician & 870 & 0,000 & -83 & 0,000 & 1006 & 0,000 & -330 & 0,000 & 52 & 0,000 \\
\hline nurse & 639 & 0,000 & -106 & 0,000 & 708 & 0,000 & -230 & 0,000 & 26 & 0,000 \\
\hline PT, OT & 916 & 0,000 & -132 & 0,000 & 1065 & 0,000 & -403 & 0,000 & 57 & 0,000 \\
\hline drugs & 284 & 0,004 & 300 & 0,000 & 307 & 0,001 & 258 & 0,011 & 9 & 0,593 \\
\hline CAM & 33 & 0,000 & $-0,5$ & 0,787 & 34 & 0,000 & $-1,4$ & 0,821 & 0,18 & 0,885 \\
\hline surgery & 111 & 0,086 & 66 & 0,011 & 50 & 0,517 & 173 & 0,036 & -23 & 0,170 \\
\hline inpatient & 323 & 0,001 & -29 & 0,327 & 389 & 0,000 & -149 & 0,052 & 25 & 0,089 \\
\hline total indir & 8147 & 0,000 & 293 & 0,109 & 8373 & 0,000 & -125 & 0,803 & 88 & 0,370 \\
\hline sick leave & 5841 & 0,000 & -952 & 0,000 & 6519 & 0,000 & $\begin{array}{r}-2 \\
169\end{array}$ & 0,000 & 256 & 0,003 \\
\hline DP & 2225 & 0,000 & 1328 & 0,000 & 1864 & 0,002 & 2000 & 0,000 & -146 & 0,120 \\
\hline total costs & 11307 & 0,000 & 279 & 0,177 & $\begin{array}{r}11 \\
884\end{array}$ & 0,000 & -792 & 0,149 & 227 & 0,035 \\
\hline
\end{tabular}

PT, OT=physiotherapist, occupational therapist, CAM=complementary medicine, $\mathrm{DP}=$ disability pension

DMARDs were instituted as judged appropriate by the treating physician. The proportion of patients being prescribed any DMARD at inclusion (1996-98) was 48\% and increased to $80 \%$ at 1 year follow up. Over the following years, DMARD prescription decreased slightly and was $70 \%$ in year 6 . The distribution of direct costs changed substantially over 6 years and an increasing part of direct costs were drug costs. In year 1, drugs constituted $10 \%$ of direct costs, increasing to $17 \%$ year 2 and to $32 \%$ year 3 . During year 4 and 5 , the corresponding values were $45 \%$ and $46 \%$ respectively and in year 6 , drugs accounted for $49 \%$ of direct costs. Besides increasing costs for biologics, there was also an increase in costs for cardiovascular drug therapy, gastro protectors, and bisphosphonates. The amount of prescribed NSAIDs also increased. Prescription of corticosteroids and analgesics remained basically unchanged over the years. There was an increase in DMARD prescription (non-biologic) during the first years, but this decreased during year 5 and 6 (fig 1). 


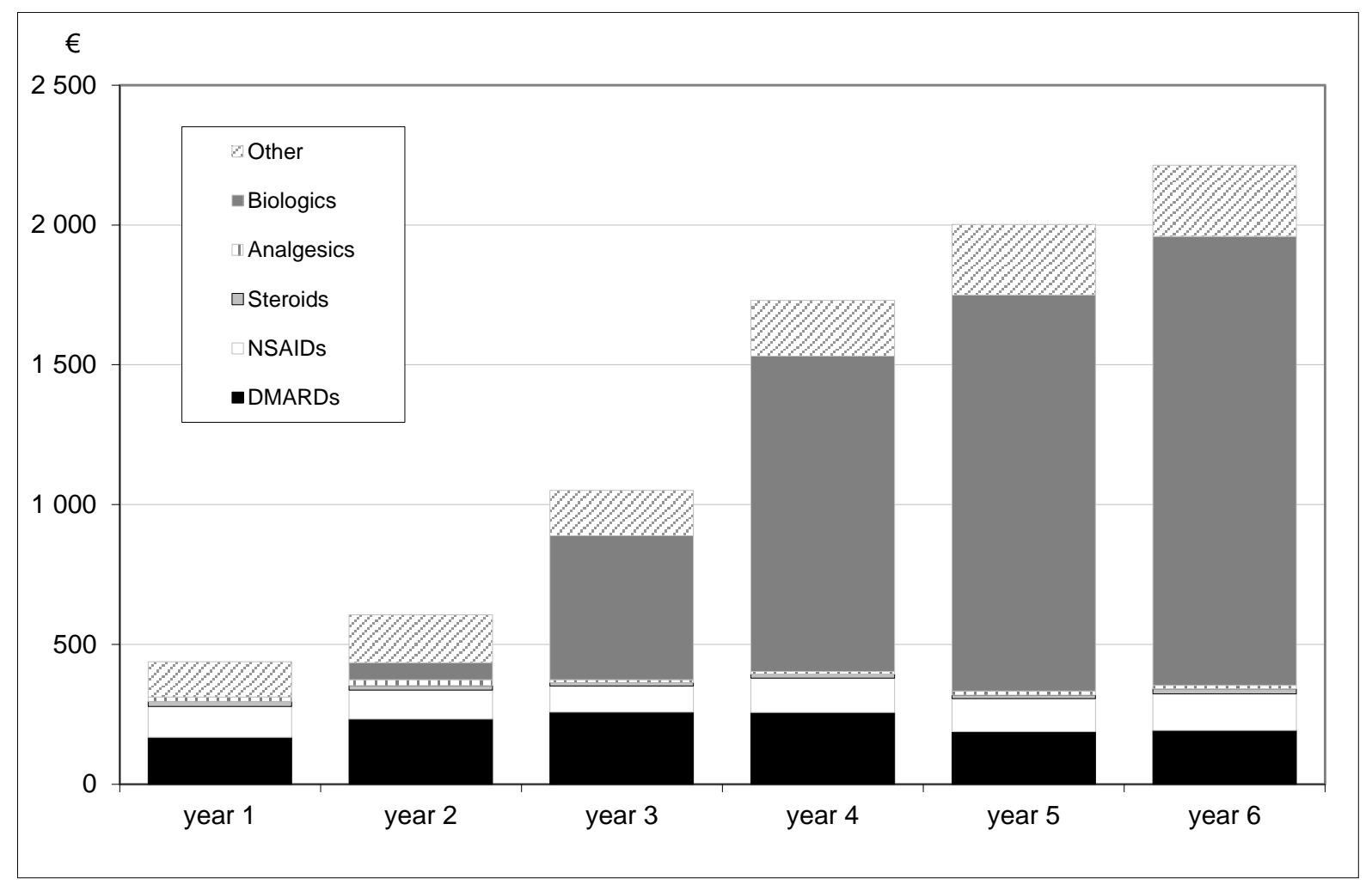

Figure 1. Costs of different groups of medications and changes over time.

During the first year, 1 total joint replacement (TJR) in hip/knee and 5 hand or foot surgeries were performed and year 2 there were 9 hand/foot/elbow surgeries and $1 \mathrm{TJR}$. Year 3 , there were $4 \mathrm{TJR}$ and $13 \mathrm{hand} /$ foot surgeries and year $4,4 \mathrm{TJR}$ and 7 hand/foot surgeries.

Corresponding values for year 5 and 6 were 8 and 7 hand/foot/elbow surgeries and 4 and 3 TJR respectively. From year 3 and onwards, a number of patients had more than 1 annual surgery. HAQ scores for patients who had surgery were substantially higher compared to $\mathrm{HAQ}$ scores for patients who did not need surgery. The number of surgeries/100 patients is shown in figure 2 together with HAQ scores for patients with and without surgery (fig 2). 


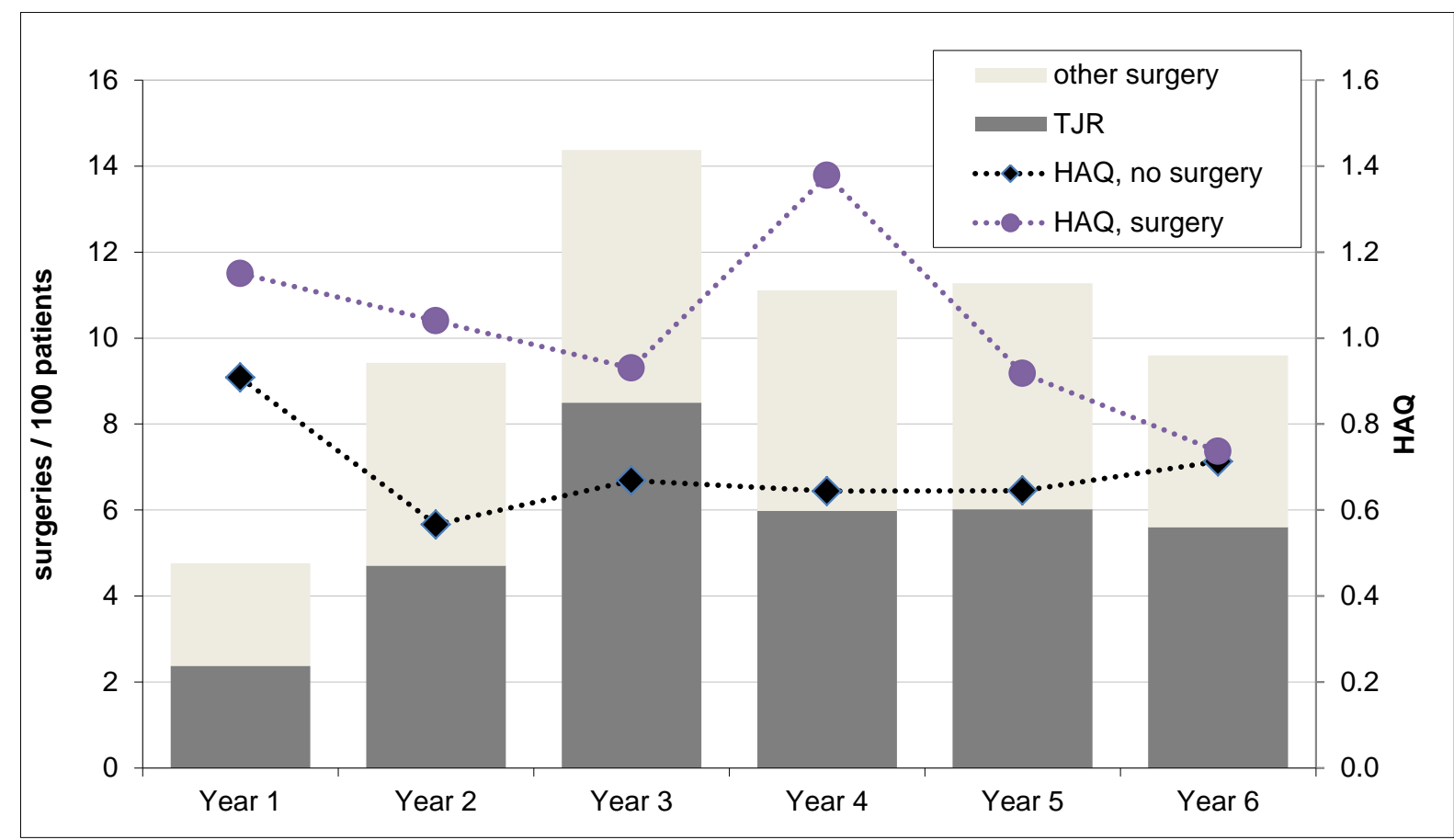

Figure 2. Number of surgeries / 100 patients. The HAQ scores represent measurements at the beginning of each year for patients who had surgery (i.e. prior to surgery) and for patients who did not have surgery. Values are given for each year.

The development of disease activity was associated with total costs. Patients who achieved remission, i.e. DAS28<2.6, had significantly lower costs all years except year 5 , compared to patients having higher DAS28 scores (fig 3).

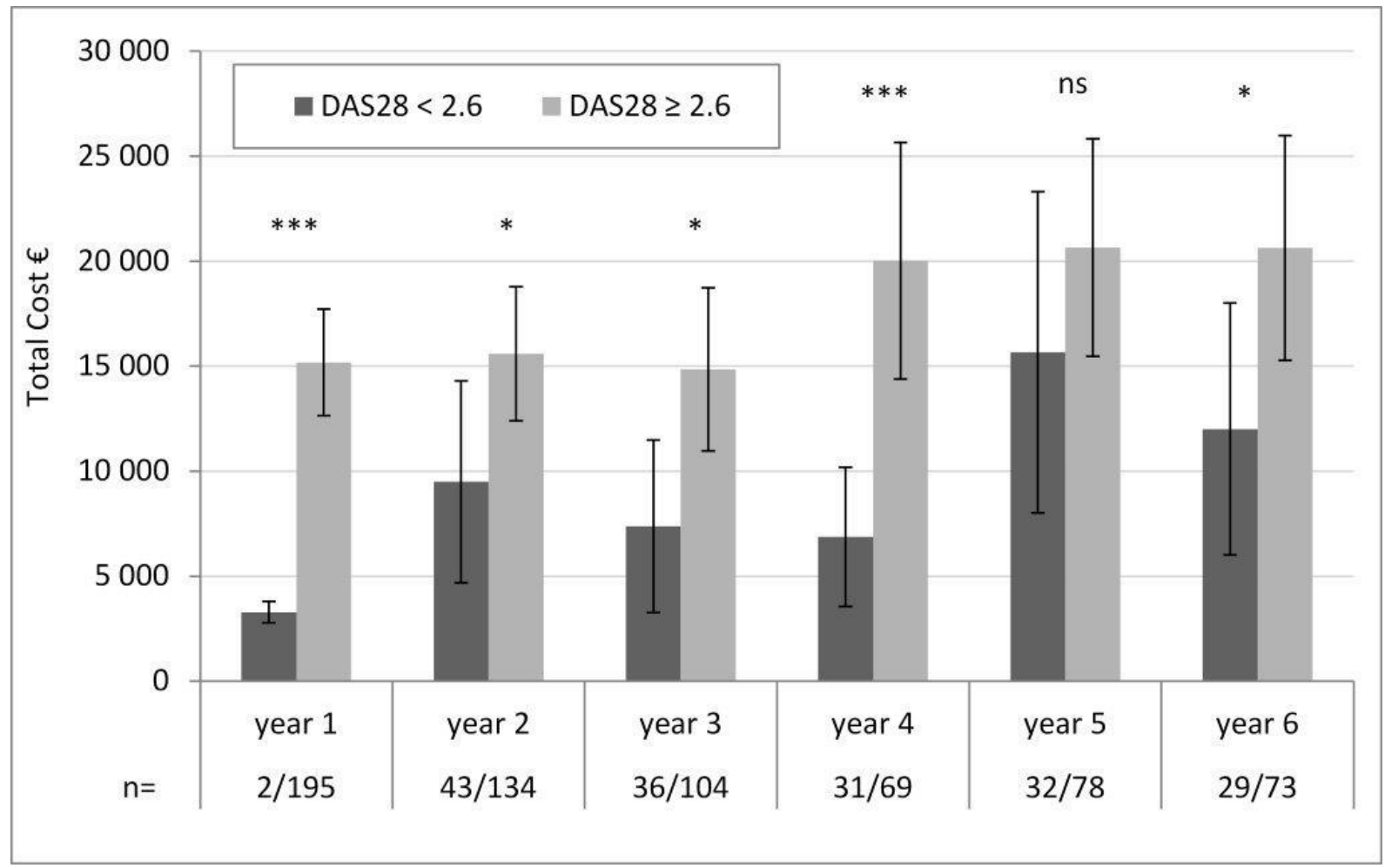

Figure 3. Total costs each year for patients with DAS28 $<2.6$ and DAS28 $\geq 2.6$ at the beginning of each year. 
Indirect costs

At baseline, $38 \%$ of the patients were retired because of age and $7 \%$ were permanently work disabled. Approximately half of the remaining patients were on sick leave and the other half were working. During the first years, the number of persons on sick leave decreased substantially, but was offset by a similar increase in persons on disability pensions. Over the following years sick leave was stabilized while disability pensions increased further (fig 4).

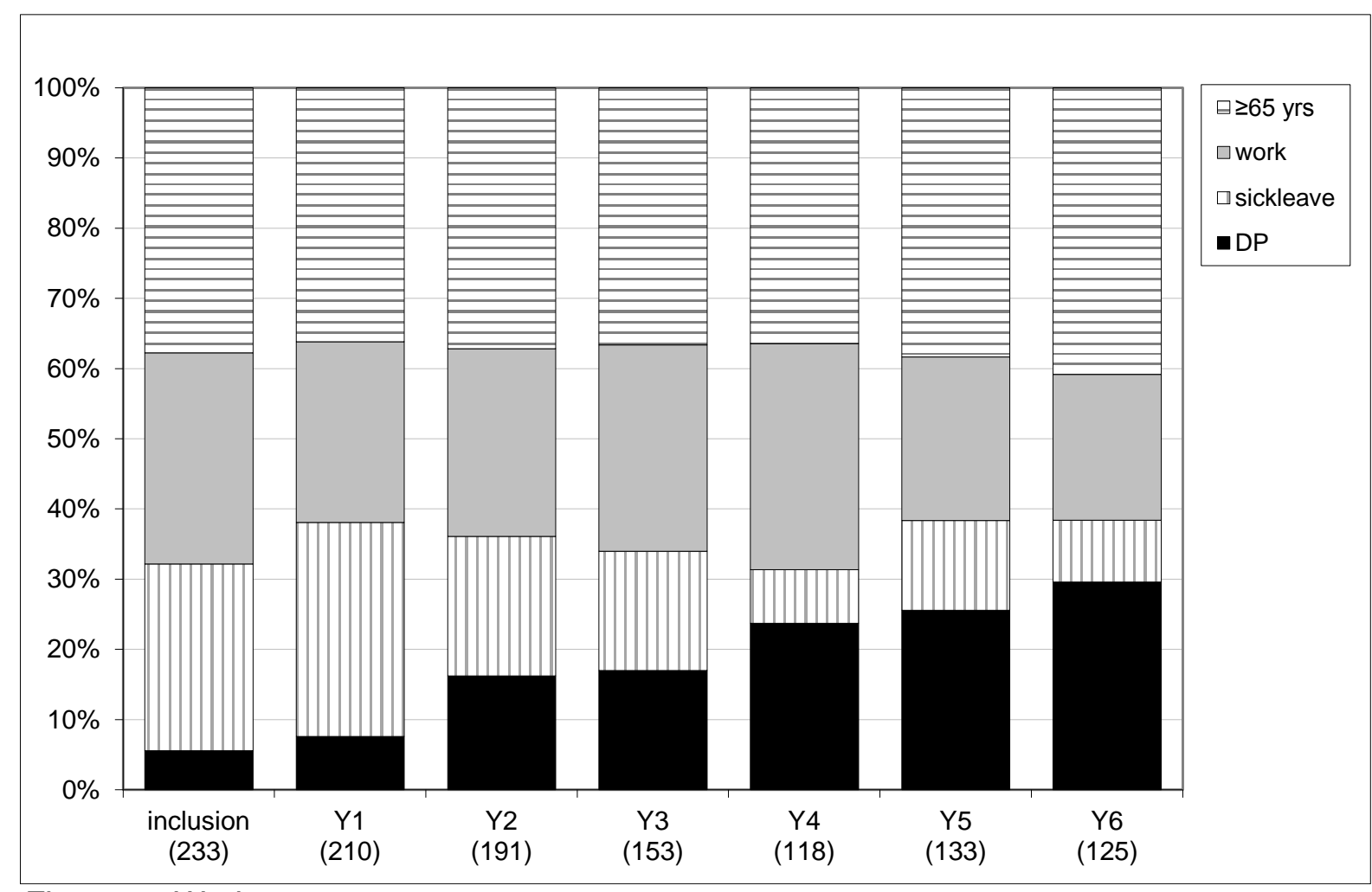

Figure 4. Work status over 6 years

\section{Discussion}

The present study reflects a period of 6 years after diagnosis of recent onset RA. During this time, there was a paradigm shift regarding management of patients with RA, including the introduction of TNF-inhibitor therapy in 1999/2000. All patients followed a study protocol, which, during the first year, rendered three outpatients visits to the physician as well as to a physiotherapist and an occupational therapist. The number of physician visits did not differ substantially from the regular follow-up routines, whereas the number of visits to physiotherapist and occupational therapist was higher during the first year compared to previous clinical routines. After slightly lowered costs during the first years, direct costs gradually increased over the following years, mainly due to increasing costs for drugs, but also due to increasing surgery and, to a minor extent, hospitalization. The clinical practice in Sweden has changed over recent years with a general shift to outpatient care instead of hospital care and when admitted, the length of stay has been shortened (22).

Indirect costs gradually increased after year 3. Patients selected for biological therapy during the first years had usually been on sick leave for a long time and this might reflect that patients with severe disease and disability had limited success in returning to work (23). Previous data on working capacity after introduction of biological treatment are conflicting. Some studies have reported a decrease in sick leave $(24,25)$, while others found no significant effect on working capacity (26-28). Two recent studies reported a decrease in sick leave, but on the other hand, increasing disability pensions $(29,30)$. 
Slightly more than half of the patients were not working at the time of inclusion. Most were on sick leave and only a few had already received disability pension, which was no surprise, considering that all had a disease duration $<12$ months. The present study coincides with a period in Sweden, when both sick leave and disability pension increased for all patients in the general population. The increasing indirect costs may partly be explained by this. Similar high levels of work disability have, however, also been reported in other inception cohorts later on $(31,32)$. Over the recent years, the incidence of disability pensions due to RA in Sweden has decreased, but simultaneously a similar declining incidence of disability pensions was seen in patients with all diagnoses in the general population. This suggests that levels of sick leave and disability pensions are to a large extent dependent on prevailing political and economic conditions in society (33). In a recent study, Sokka et al showed that macroeconomic variables have a large potential to influence the patient's working capacity, maybe even to a larger extent than the disease activity per se (26).

Rates of disability pension may differ between countries due to differences in social security systems $(26,34)$. In the present study, costs were calculated, using the human capital approach (HCA). The same average income has however been used for all patients, regardless gender or occupation, in order primarily not to focus on differences in salary. This average salary was, in fact, approximately the same as the average salary of the general population, when adjusted for age and gender similar to that of the TIRA cohort (17). Indirect costs can also be calculated using the alternative friction cost method (FC), assuming that an unemployed individual will replace the absent worker after a period of absenteeism. The human capital method may lead to an overestimation of costs compared to the FC, but has a stronger theoretical underpinning and is the most commonly used method in health economic evaluations $(35,36)$.

Despite the intention in the TIRA project, to institute DMARDs rapidly, the proportion of patients without any DMARD treatment was rather high and increased after the 1-year follow-up. More recently, an early and more aggressive approach with DMARDs has gradually been implemented to treat RA patients, and there is increasing evidence that biological drugs could make a difference, if initiated earlier in the disease course (37). Disease activity progression and increasing functional disability are associated with increased direct and indirect costs (38). In the present study, disease activity (assessed by DAS28) decreased rapidly during the first year and decreased further over the following 6 years from 3.8 to 3.3. Despite decreasing disease activity, costs continued to increase and this was most pronounced in the vast majority of patients, not achieving remission. Functional disability, as measured by $\mathrm{HAQ}$, also improved substantially during the first year, but unlike the DAS28, HAQ slowly deteriorated during the same time and this discrepancy was maintained over the years which may suggest that costs are affected differently by disease activity and disability, although these variables are likely overlap to a great extent. It must be emphasized, however, the DAS28 algorithm takes into account other variables than disease activity due to inflammation, e.g. non-inflammatory pain and psychological factors affecting quality of life.

A number of patients were lost to follow-up over the years and this is a limitation. Since they were slightly older than patients remaining in the study, this may have lowered the direct costs. Cost estimates were based upon self-reported data and recall bias cannot be ruled out. The questionnaires were, however, distributed at the preceding visit and were kept as diaries during the whole period. In general, the patients provided very detailed information on medication, hospitalization and surgical interventions. All medication prescribed, both due to RA and to other disease manifestations (e.g. cardiovascular events and infections) was reported. This might slightly have overestimated drug costs, since some events may have been unrelated to RA. However, patients' out-of-pocket costs as well as non-medical costs such as transportation costs and purchase of devices were not taken into account. Since these costs can be substantial, the total direct costs were probably underestimated. In 
addition, work-related factors, such as having blue-collar or white-collar jobs, have a large impact on the ability to work and hence indirect costs. These data were, however, not available. A strength of the present study is the well-characterized patient material and the longitudinal prospective design with regular follow-ups, allowing analyses of long-term outcomes of patients with early RA. Most studies have been performed cross-sectionally or have examined cost data over shorter time spans.

To conclude, drug costs were partially offset by decreasing outpatient visits but even so, the total costs increased every year.

\section{References}

1. Hallert E, Björk M, Dahlström $O$, Skogh $T$, Thyberg I. Disease activity and disability in women and men with early rheumatoid arthritis (RA): an 8-year followup of a Swedish early RA project. Arthritis Care Res 2012;64:1101-7

2. .Kvien TK. Epidemiology and burden of illness of rheumatoid arthritis. Pharmacoeconomics 2004;22 Suppl 1:1-12.

3. Hallert E, Husberg M, Jonsson D, Skogh T. Rheumatoid arthritis is already expensive during the first year of the disease (the Swedish TIRA Project). Rheumatology 2004; 43:1374-82.

4. Sokka T. Work disability in early rheumatoid arthritis. Clin Exp Rheumatol 2003;21:S714.

5. Franke LC, Ament AJ, van de Laar MA, Boonen A, Severens JL. Cost-of-illness of rheumatoid arthritis and ankylosing spondylitis. Clin Exp Rheumatol 2009;27:S118-23.

6. Burmeister GD. RA in 2011: advances in diagnosis, treatment and definition of remission. Nature Rev Rheumatol 2012;8:65-6.

7. Breedvelt FC, Combe B. Understanding emerging treatment paradigms in rheumatoid artrhritis. Arthritis Res Ther 2011;13 Suppl 1:S3

8. Tak PP, Kalden JR. Advances in rheumatology: new targeted therapeutics. Arthritis Res Ther 2011; Suppl 1:S5.

9. Gülfe A, Kristensen LE, Saxne T, Jacobsson LT, Petersson IF, Geborek P. Rapid and sustained health utility gain in anti-tumour necrosis factor-treated inflammatory arthritis: Observational data during 7 years in southern Sweden. Ann Rheum Dis 2010;69:352-7

10. Wolfe F, Michaud K. The loss of health status in rheumatoid arthritis and the effect of biologic therapy: a longitudinal observational study. Arthritis Res Ther 2010;12:R35.

11. van Vollenhoven RF, Geborek P, Forslind K, Albertsson K, Ernestam S, Petersson IF et al. Conventional combination treatment versus biological treatment in methotrexaterefractory early rheumatoid arthritis: 2 year follow-up of the randomised, non-blinded, parallel-group Swefot trial. Lancet 2012;379:1712-20.

12. Hallert $E$, Husberg $M$, Skogh $T$. Costs and course of disease and function in early rheumatoid arthritis: a 3-year follow-up (the Swedish TIRA project). Rheumatology 2006 45:325-31.

13. Arnett FC, Edworthy SM, Bloch DA, McShane DJ, Fries JF, Cooper NS et al. The American rheumatism association 1987 revised criteria for the classification of rheumatoid arthritis. Arthritis Rheum 1988;31:315-24.

14. Prevoo MLL, van't Hof MA, Kuper HH, van Leeuwen MA, Van de Putte LBA, van Riel. Modified disease activity scores that include twenty-eight-joint counts. Arthritis Rheum 1995;38:44-8.

15. Svärd A, Kastbom A, Reckner-Olsson A, Skogh T. A comparison between IgG- and IgAclass antibodies to cyclic citrullinated peptides and to modified citrullinated vimentin in early rheumatoid arthritis and very early arthritis. J Rheumatol 2011;38:1265-72.

16. Ekdahl C, Eberhardt KB, Andersson SI, Svensson B. Assessing disability in patients with rheumatoid arthritis. Scand J Rheumatol 1988;17:263-71.

17. www.scb.se Statistics, Sweden. 
18. www.riksbank.se

19. www.skl.se. Federation of Swedish County Councils (Landstingsförbundet). Stockholm

20. Serden L, Lindquist R, Rosen M. Have DRG-based prospective payment systems influenced the number of secondary diagnoses in health care administrative data? Health Policy 2003;65:101-17.

21. www.fass.se

22. Petersson IF.Team care.Traditions and new trends. J Rheumatol 2006;33:1895-6.

23. Zirkzee EJ, Sneep AC, de Buck PD, Allaart CF, Peeters AJ, Ronday HK et al. Sick leave and work disability in patients with early arthritis. Clin Rheumatol 2008;27:11-9.

24. Smolen JS, Han C, van der Heijde D, Emery $P$, Bathon JM, Keystone E et al. Infliximab treatment maintains employability in patients with early rheumatoid arthritis. Arthritis Rheum 2006;54:716-22.

25. Bejarano V, Quinn M, Conaghan PG, Reece R, Keenan AM, Walker D et al. Effect of the early use of the anti-tumor necrosis factor adalimumab on the prevention of job loss in patients with early rheumatoid arthritis. Arthritis Rheum 2008;59:1467-74.

26. Sokka T, Kautiainen H, Pincus T, Verstappen SM, Aggarwal A, Alten R et al. Work disability remains a major problem in rheumatoid arthritis in the 2000s: Data from 32 countries in the QUEST-RA study. Arthritis Res Ther 2010;12:R42

27. Wolfe F, Allaire S, Michaud K. The prevalence and incidence of work disability in rheumatoid arthritis, and the effect of anti-tumor necrosis factor on work disability. $\mathrm{J}$ Rheumatol 2007;34:2211-7.

28. Allaire S, Wolfe F, Niu J, Zhang Y, Zhang B, LaValley M. Evaluation of the effect of antitumor necrosis factor agent use on rheumatoid arthritis work disability: the jury is still out. Arthritis Rheum 2008;59:1082-9.

29. Olofsson T, Englund M, Saxne T, Jöud A, Jacobsson LT, Geborek P, et al. Decrease in sick leave among patients with rheumatoid arthritis in the first 12 months after start of treatment with tumour necrosis factor antagonists: A population-based controlled cohort study. Ann Rheum Dis 2010;69:2131-6.

30. Neovius M, Simard JF, Askling J; ARTIS Study Group. How large are the productivity losses in contemporary patients with RA, and how soon in relation to diagnosis do they develop? Ann Rheum Dis 2011;70:1010-5

31. Merkesdal S, Ruof J, Huelsemann JL, Mittendorf T, Handelmann S, Mau W et al. Indirect cost assessment in patients with rheumatoid arthritis (RA): comparison of data from the health economic patient questionnaire HEQ-RA and insurance claims data. Arthritis Rheum 2005;53:234-40.

32. Eriksson JK, Neovius M, Bratt J, Petersson IF, van Vollenhoven RF, Geborek $P$ et al. Biological vs Conventional Combination Treatment and Work Loss in Early Rheumatoid Arthritis: A Randomized Trial. JAMA Intern Med 2013 Jul 1 (Epub ahead of print)

33. Hallert $E$, Husberg M, Bernfort L. The incidence of permanent work disability in patients with rheumatoid arthritis in Sweden 1990-2010: before and after introduction of biologic agents. Rheumatology 2012;51:338-46

34. Chung CP, Sokka T, Arbogast PG, Pincus T. Work disability in early rheumatoid arthritis: higher rates but better clinical status in Finland compared with the US. Ann Rheum Dis 2006;65:1653-7

35. Merkesdal S, Ruof J, Schöffski O, Bernitt K, Zeidler H, Mau W. Indirect medical costs in early rheumatoid arthritis: composition of and changes in indirect costs within the first three years of disease. Arthritis Rheum 2001;44:528-34

36. Koopmanschap MA, Rutten FF. A practical guide for calculating indirect costs of disease, Pharmacoeconomics 1996;10:460-6.

37. Emery P, Kvien TK, Combe B, Freundlich B, Robertson D, Ferdousi T et al. Combination etanercept and methotrexate provides better disease control in very early ( $\leq 4$ months) versus early rheumatoid arthritis ( $>4$ months and $<2$ years): post hoc analyses from the COMET study. Ann Rheum Dis 2012;6:989-92. 
38. Furneri G, Mantovani LG, Belisari A, Mosca M, Cristiani M, Bellelli S et al. Systematic literature review on economic implications and pharmacoeconomic issues of rheumatoid arthritis. Clin Exp Rheumatol 2012;30:S72-84 